\title{
Persistent asthma after accidental exposure to ethylene oxide
}

\author{
D Deschamps, N Rosenberg, P Soler, G Maillard, E Fournier, D Salson, P Gervais
}

Ethylene oxide is a reactive epoxy compound widely used as a precursor for industrial chemicals and, to a lesser extent, as a disinfecting and sterilising agent. ${ }^{1}$ In recent years the occupational hazards of ethylene oxide, particularly leukaemia, ${ }^{23}$ peripheral and central neuropathies, ${ }^{45}$ and cataracts $^{67}$ have been investigated. Occupational asthma has not so far been described.

\section{Case report}

A 35 year old non-smoking, non-alcoholic, and non-diabetic man was referred to our clinic because of asthma.

He worked as a repairer in a railway station and had never been occupationally exposed to any chemicals until he experienced a leak of ethylene oxide from a wagon situated about $18 \mathrm{~m}$ from him when he had no protective respiratory equipment. The smell indicated a high atmospheric concentration (over $700 \mathrm{ppm}$ ). ${ }^{8}$ After four days of four hours of daily exposure he developed coughing, shortness of breath, and wheezing in the work place. These symptoms persisted with daily attacks despite removal from exposure and continuous treatment with a $\beta$-2-agonist and theophylline. He had no preceding respiratory complaints. Tests of pulmonary function one year after the accident showed a bronchial obstruction (forced vital capacity (FVC) $4.65 \mathrm{l} / \mathrm{s}, 93 \%$ of predicted; forced expiratory volume in one second $\left(\mathrm{FEV}_{1}\right) 3.051,74 \%$ of predicted; and maximum

Service de médecine interne et de toxicologie clinique, Hôpital Fernand Widal, 75475 Paris cedex 10, France

D Deschamps, N Rosenberg, G Maillard, P Gervais

INSERM U 82, Faculté Xavier Bichat, 75018 Paris, France

P Soler

Service d'exploration fonctionnelle du système nerveux, Hôpital la Pitié-Salpétrière, 75634 Paris cedex 13, France

E Fournier

Société Nationale des Chemins de Fer Français, 75010 Paris, France

D Salson mid-expiratory flow rate $\left(\mathrm{FEF}_{25-75}\right) 2 \cdot 25 \mathrm{l} / \mathrm{sec}$, $44 \%$ of predicted) reversible by treatment with a $\beta$-2-agonist and a bronchial hyperreactivity $\left(\mathrm{FEV}_{1}\right.$ fell by $20 \%$ with $600 \mu \mathrm{g}$ acetylcholine).

The patient was referred to our department three years after the accident. His clinical respiratory state and his pulmonary function were unchanged. Diffusing capacity for carbon monoxide, chest $x$ ray film, and thorax computer examination were normal. He was not atopic as skin tests for 14 aeroallergens were negative and serum IgE concentration was normal $(41 \mathrm{kUI} / 1)$. No specific IgE to ethylene oxide was detected (radioallergosorbent test with a commercial kit from Pharmacia). Bronchial histology showed mucus hyperplasia, but only a slight inflammatory response, with spare lymphocytes and polymorphonuclear cells and no eosinophils. Examination by transmission electron microscopy showed partial epithelial destruction and thickening of the subepithelial connective tissue; only a slight inflammatory response was found, without alteration of the tight junctions or cilia; no thickening of the basement membrane had occurred (figure).

Neurological examination showed that a sense of position was abnormal in the toes, and ankle jerks were decreased. Motor and sensory nerve conduction velocities and electromyography were normal, but the maximum amplitudes of the right and left $\mathrm{H}$ reflex responses were significantly reduced $(6 \%$ and $2 \%$ of the maximum amplitude of the soleus direct response respectively) without decrease in proximal conduction velocity, indicating a slight sensitive proprioceptive axonal neuropathy. ${ }^{9}$ Ophthalmological examination (particularly of the lens) was normal, as was white blood cell count (leucocytes $4900 / \mathrm{mm}^{3}$; polymorphonuclear cells $3100 / \mathrm{mm}^{3}$; lymphocytes $1650 / \mathrm{mm}^{3}$ ).

None of the other five exposed workers had respiratory complaints. Three were examined in our clinic (two were atopic subjects, one of whom was asthmatic before the accident). We found no bronchial hyperreactivity in the two nonasthmatic subjects; the asthmatic worker did not 


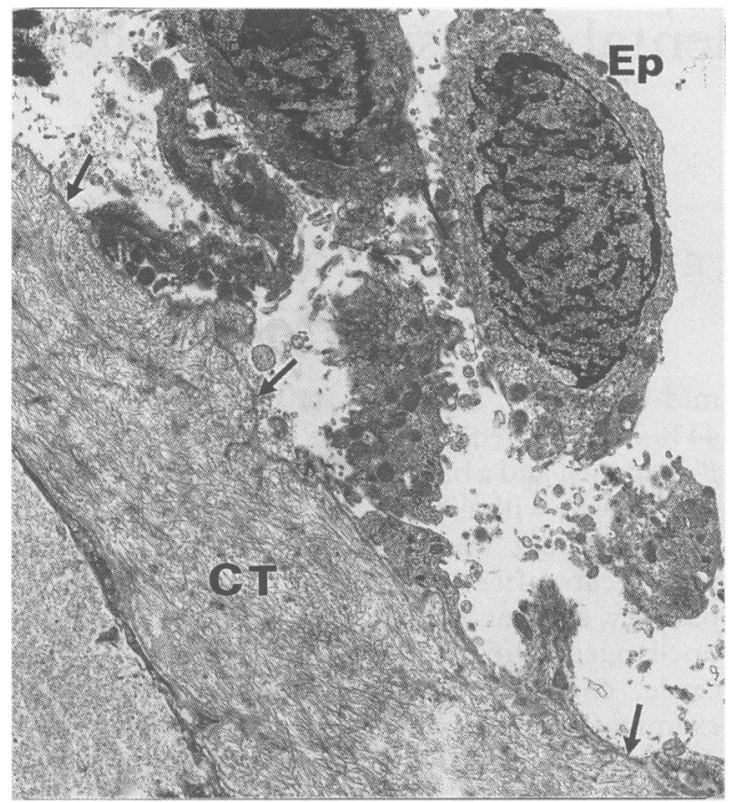

Electron microscopical examination of bronchial biopsy

specimen. Most epithelial cells ( $E p)$ are altered or destroyed leading to a denuded basal lamina (arrows). The

subepithelial connective tissue $(C T)$ is thickened $(\times 7750)$.

have worse attacks after the accident. None had clinical or subclinical neurological abnormalities.

\section{Discussion}

This case of occupational asthma as a result of ethylene oxide (the first case as far as we know) occurred after only four days of four hours of acute exposure.

Ethylene oxide is widely used for sterilisation of dialysis equipment and has been found in substantial amounts in the rinsing fluid of sterilised dialysers. In patients on regular dialysis treatment, asthma is commonly associated with high values of ethylene oxide-IgE antibodies, and in vitro studies suggest that human albuminethylene oxide conjugates may induce IgE mediated degranulation of basophils in sensitised dialysis patients. ${ }^{10}$

By contrast, a non-immunological mechanism seems operative here. The rapid onset of the symptoms, the high atmospheric concentration of ethylene oxide (also possibly responsible for the slight neurological abnormality), the persistence of symptoms after removal from exposure, and the absence of ethylene oxide-IgE antibodies argue for a reactive airways dysfunction syndrome, ${ }^{11}$ for example, persistent asthma after high irritant exposure. The time between the start of exposure and onset of symptoms is too short to explain the involvement of a sensitising mechanism in the pathogenesis of the initial dyspnoea. Moreover, persistence of the asthma cannot be the result of further exposure: this case should be differentiated from occupational asthma after intense short term exposure to a sensitising agent. ${ }^{12}$ On the contrary the alkylating properties of ethylene oxide probably explain why symptoms occurred only after the fourth day of exposure, alkylating injuries taking longer to appear than direct irritating or caustic injuries.

As previously described for this syndrome, bronchial biopsy samples showed respiratory epithelial injury with a mild chronic unspecific inflammatory response; the lack of eosinophils is unusual in asthma. ${ }^{13}$ Electron microscopy (previously not performed on patients with this syndrome) showed a subepithelial fibrosis without thickening of the basement membrane, as seen in asthma. ${ }^{14}$ So, these findings do not support pulmonary inflammation (responsible for a change in histamine response, perhaps by increasing bronchial smooth muscle response to histamine) or increased epithelial permeability (with subtle disturbance of subcellular components such as tight junctions beneath which are located vagal sensory nerve endings) as primary hypotheses for this persistent asthma. On the contrary, an extensive epithelial injury probably has an important role: the regeneration of epithelial tissue is incomplete and contributes to the moderate inflammation leading to fibrosis. Moreover, subepithelial irritant receptors, superficial in location, could be affected; subsequent regeneration of epithelial tissue with probable reinnervation of the bronchial mucosa might drastically alter the threshold of the receptors and cause hyperreactivity of airways.

As previously described ${ }^{115}$ atopy or preexisting respiratory disease do not seem to predispose to this syndrome, which occurred in only one of the six exposed workers, probably because of a more severe exposure in that man.

We conclude that although occupational asthma usually occurs through immunological mechanisms in workers exposed to low concentrations of chemicals for a long period, it should also be recognised after short accidental exposure to high concentrations of irritant or alkylating gas. ${ }^{11}$ Further investigations into the role of nonimmunological environmental and occupational factors in the pathogenesis of this syndrome of reactive airways dysfunction are warranted.

We thank S Dally for reviewing the manuscript. 
Requests for reprints to: Dr Deschamps, Hôpital Fernand Widal, 200 rue du faubourg Saint Denis, 75475 Paris Cedex 10, France.

1 National Institute for Occupational Safety and Health. National occupational exposure survey: sampling methodology. Cincinnati: Department of Health and Human Services. 1990. nati: Department of Health and

2 Hogstedt C, Malmqvist N, Wadman B. Leukemia in workers exposed to ethylene oxide. JAMA 1979;241:1132-3.

3 Steenland K, Stayner L, Greife A, et al. Mortality among workers exposed to ethylene oxide. New Engl J Med 1991;324: 1402-7.

4 Gross JA, Hass ML, Swift TR. Ethylene oxide neurotoxicity: report of four cases and review of the literature. Neurology 1979;29:978-83.

5 Estrin WJ, Bowler RM, Lash A, Becker CE. Neurotoxicological evaluation of hospital sterilizer workers exposed to ethylene oxide. J Toxicol Clin Toxicol 1990;28:1-20.

6 Jay WM, Swift TR, Hull DS. Possible relationship of ethylene oxide exposure to cataract formation. Am J Ophthalmol 1982; 93:727-32.

7 Deschamps D, Leport M, Laurent AM, Cordier S, Festy B,
Conso F. Toxicity of ethylene oxide on the lens and on leukocytes: an epidemiological study in hospital sterilisation installations. $\mathrm{Br} J$ Ind $\mathrm{Med}$ 1990;47:308-13.

8 Jacobson KH, Hackley EB, Feinsilver L. The toxicity of ethylene oxide and propylene oxide vapors. $A M A$ Arch Ind Health 1956;13:237-43.

9 Troni $W$. Analysis of conduction velocity in the $H$ pathway, part I: methodology and results in normal subjects. $J$ Neurol $S c i$ 1981;51:223-33.

10 Rumpf KW, Seubert S, Seubert A, et al. Association of ethylene-oxide-induced IgE antibodies with symptoms in dialysis patients. Lancet 1985;ii:1385-7.

11 Brooks SM, Weiss MA, Bernstein IL. Reactive airways dysfunction syndrome: persistent asthma syndrome after high level irritant exposures. Chest 1985;88:376-84.

12 Boulet LP. Increases in airway responsiveness following acute exposure to respiratory irritants: reactive airway dysfunction syndrome or occupational asthma? Chest 1988;94:476-81.

13 Bousquet J, Chanez P, Lacoste JY, et al. Eosinophilic inflammation in asthma. New Engl J Med 1990;323:1033-9.

14 Roche WR, Beasley R, Williams JH, Holgate ST. Subepithelial fibrosis in the bronchi of asthmatics. Lancet 1989;i :520-4.

15 Cordasco EM, Demeter S, Cordasco In EM, McCarthy K, Lubs $P$, Cassidy J. Reactive airways dysfunction syndrome. Newers aspects. In: Proceedings of the 23rd international congress of occupational health. Montreal, Canada: 22-28 September 1990.

Accepted 7 October 1991 